\title{
Apply of Explicit Finite Element in Seismic Ground Motion Computation*
}

\author{
Yuzhu Bai, Xiwei Xu \\ Active Tectonics and Volcano Lab, Key Lab of China Earthquake Administration, Beijing, China \\ Email: yuzhubai2008@126.com
}

Received August 2013

\begin{abstract}
In this paper, we will use the explicit finite element to compute ground motion due to Tangshan earthquake. The explicit finite-element method uses one integration point and an hourglass control scheme. We implement the coarse-grain method in a structured finite-element mesh straightforwardly. At the same time, we also apply the coarse-grain method to a widely used, slightly unstructured finite-element mesh, where unstructured finite elements are only used in the vertical velocity transition zones. By the finite-element methods, we can compute the ground velocity with some distance to the seismogenic fault in Tangshan earthquake. Through the computation, we can find the main character of ground motion for the strike slip earthquake events and the high frequency vibration motion of ground motion.
\end{abstract}

Keywords: Finite-Element Method; Fault; Ground Motion; Tangshan Earthquake

\section{Introduction}

In earthquake research, we often mainly apply the finitedifference and finite-element method to calculate the ground motion due to the movement of the seismic faults. The finite-element method, one of the most popular methods in the engineering science, is increasingly used in earthquake computation (see [1-3]) and earthquake dynamic rupture propagatios (see [4,5]). With the help of irregular elements of different size, geometry, and order of approximations, the finite-element is efficient to model complicated geometrical boundary conditions at present.

The explicit finite-element method with second-order elements and one-point integration is widely used. This method combines the flexibility of the finite-element method and the efficiency of finite-difference method. As its efficiency and versatility, this method has been widely implemented and applied to transient analyses in engineering and seismology. Here, we refer to this particular implementation as the explicit finite-element method.

The following algorithm for the explicit finite-element method is easy. Usually, it uses for-node quadrilateral elements in two dimensions and eight-node hexahedral elements in three dimensions and applies one integration point and an hourglass control scheme. Because of the computational costs and the numerical noise resulting

"Subsidized by "Discern and evaluation of earthquake risk zone (2012BAK15B01)”. from the ad hoc mass lumping necessary to generate a diagonal mass matrix (see [6]), higher-order elements are rarely used in researching transient problems. But onepoint integration provides tremendous computational benefits in dynamic simulations. Comparing with the full integration, one-point integration has a 3/4 reduction in computational time in two dimensions and 7/8 reduction in three dimensions. At the same time, one-point integration also provides the efficient way to simulate nonlinear material response (see [7]).

In fact, the one-point integration in the elements has its own drawback which is a mesh instability known as hourglassing. But the hourglass modes can be eliminated by well-developed hourglass control schemes (see [8]). Kosloff and Frazier [9] had showed that a one-point integration implementation coupled with a stiffness hourglass control scheme can produce a more accurate flexural response than fully integrated elements. So in this article, we will apply the finite-element with one-point integration developed by Ma [10] to compute the ground velocity of some locations varying with time in the Tangshan earthquake.

\section{Explicit Finite-Element Algorithm and Tectonic Background}

\subsection{Explicit Finite-Element Algorithm}

Here we will use the explicit finite element developed by Ma [10], so we will introduce his method in a simple 
way. The details of method introduction can be found in his article. For an eight-node hexahedral isoparametric element, the trilinear shape function is given in the reference plane by

$$
N_{I}=\left[\left(1+\xi_{I} \xi\right)\left(1+\eta_{I} \eta\right)\left(1+\zeta_{I} \zeta\right)\right] / 8
$$

In (1), $(\xi, \eta, \zeta)$ is the coordinate of an arbitrary point within the element in the reference plane and $\left(\xi_{I}, \eta_{I}, \zeta_{I}\right)$ is the coordinate of node $I$. The range of the upper-case subscripts is $\{1-8\}$. The transformation between the physical plane and the reference plane is following:

$$
x=x_{I} N_{I} ; y=y_{I} N_{I} ; z=z_{I} N_{I}
$$

In (2), $(x, y, z)$ is the coordinate of an arbitrary point within the element in the physical plane and $\left(x_{I}, y_{I}, z_{I}\right)$ is the coordinate of node. Summation over repeated indices is applied. In the element, the velocity field can be expressed by the same shape function as:

$$
v_{i}=v_{i l} N_{I}
$$

where $v_{i l}$ is the velocity of node. The range of lower case subscripts is $\{1,2,3\}$. In the one-point integration finite-element scheme, the velocities are located at the element nodes and the stresses are all defined at the center of the element.

If defined the matrix as

$$
B_{i I}=\left.N_{I, i}\right|_{\xi=\eta=\zeta=0}
$$

where the comma denotes differentiation, then the velocity gradient at the element center is

$$
v_{i, j}=v_{i l} B_{j I}
$$

By the Equation (4), it can be found that the $B$ matrix has the antisymmetry properties. The detailed derivation of the $B$ matrix is shown in appendix A of [10]. Through the velocity gradient, we can calculate the element stress rate at the element center by following

$$
\dot{\sigma}_{i j}=\lambda \delta_{i j} v_{l, l}+\mu\left(v_{i, j}+v_{j, i}\right)
$$

where $\lambda$ and $\mu$ are the Lame's constants of the element and $\delta_{\mathrm{ij}}$ is the Kronecker delta. The nodal force rate caused by the stress rate within the element is given by

$$
f_{i l}^{\text {stress }}=V B_{j I} \sigma_{i j}
$$

where $V$ is the element volume. The applying of onepoint integration can result in certain deformation modes remain stressless. These zero-stress modes are hourglass modes. The amplitudes of the hourglass modes in the element are given by

$$
q_{i \alpha}=v_{i l} \varphi_{\alpha I}
$$

where Greek subscripts have a range of $\{1,2,3,4\}$ and the hourglass base vector $\varphi_{\alpha}$ is defined as:

$$
\begin{aligned}
& \varphi_{1}=\{11-1-1-1-111\} \\
& \varphi_{1}=\{1-1-11-111-1\} \\
& \varphi_{1}=\{1-11-11-11-1\} \\
& \varphi_{1}=\{-11-111-11-1\}
\end{aligned}
$$

In the viscous hourglass control scheme, the hourglass forces can be approximated by

$$
f_{i l}^{v h g}=\chi \rho V_{p} V^{2 / 3} q_{i \alpha} \varphi_{\alpha I}
$$

where $\rho$ and $V_{\mathrm{P}}$ are the density and the $P$-wave velocity of the element, and $\chi$ is a tunable parameter that is usually set in the range $0.05-0.15$ (see [7]).

If a stiffness hourglass control scheme is used, the stiffness hourglass force rates can be approximated by:

$$
f_{i I}^{\dot{e h g}}=\frac{\kappa}{16}(\lambda+2 \mu) V^{1 / 3} q_{i \alpha} \varphi_{\alpha I}
$$

where the tunable parameter $\kappa$ is usually 0.3 . The total elastic nodal force rate caused by both the stress and hourglass modes is given by

$$
f_{j I}^{\text {elastic }}=f_{j I}^{\text {stress }}+f_{j I}^{\text {ehg }}
$$

\subsection{The Tectonic Background of Tangshan Earthquake}

On 28 July 1976, a destructive earthquake struck the city of Tangshan, in mainland China, $160 \mathrm{~km}$ east of Beijing. The focal depth of the $M_{\mathrm{S}}=7.8$ Tangshan earthquake was $10 \mathrm{~km}$ [Bulletin of the International Seismological Center (ISC)]. A prominent surface rupture crossed the city of Tangshan, it completely destroyed the city and heavily damaged the surrounding areas. The largest aftershock ( $M_{\mathrm{s}}=7.1$ Luanxian earthquake) occurred approximately $45 \mathrm{~km}$ northeast of the mainshock on the same day. Another large aftershock $\left(M_{\mathrm{S}}=6.9\right.$ Ningho earthquake) happened on 15 Novermber 1976 and was located southwest of Tangshan near Ningho. The 1976 Tangshan, China, earthquake of $M_{\mathrm{S}} 7.8$ killed 242,000 persons, seriously injured 164,000 persons, and caused direct property losses totaling 8 billion Yuan Ren Min Bi.

Figure 1 shows a map view of the Tangshan fault and the fault near to Tangshang. Tangshan lies near the northern boundary of the China Basin, a seismically active region with at least nine large, destructive earthquakes since $1600 \mathrm{~A} \mathrm{D}$. The tectonics is characterized by active subsidence in right step-overs between predominatly north-northeast trending, right-lateral strike-slip faults. After the Tangshan earthquake, the mechanisms of the Tangshan events had been studied by many scholars. 
These studies showed that the mainshock consisted of two subevents, separated by about $10 \mathrm{sec}$, with rightlateral strike-slip motion on two near-vertical northnortheast trending faults. The first subevent initiated near the junction of the two segments and the junction to the north.

\section{Earthquake Model and Focus Parameters}

In the Figure 1, we will computation $\rightarrow$ compute the zone which covers $140 \mathrm{~km}$ along strike direction, $210 \mathrm{~km}$ vertical to strike direction and $40 \mathrm{~km}$ in depth direction. In the finite element model, the calculating parameters are listed in Table 1. In our explicit finite-element method, we set the spatial and time step is $500 \mathrm{~m}$ and $0.05 \mathrm{~s}$ respectively. The duration of computation is 40 seconds.

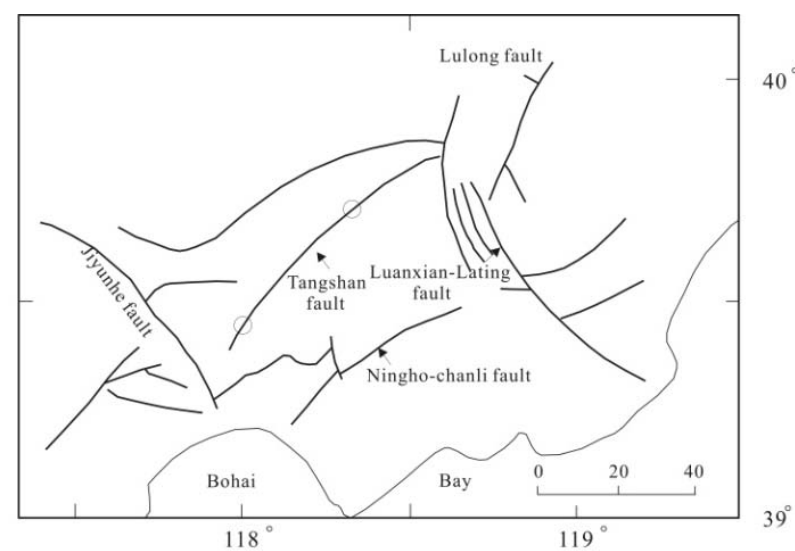

Figure 1. The fault location of Tangshan earthquake.

Table 1. The calculating parameters.

\begin{tabular}{ll}
\hline Type of Parameters & value \\
\hline Earthquake magnitude & 7.8 \\
Focus location & $39.6^{\circ}$ \\
& $118.2^{\circ}$ \\
Fault size & $48 \mathrm{~km}(\mathrm{~L})$ \\
Focus depth & $20 \mathrm{~km}(\mathrm{~W})$ \\
Strike direction & $15 \mathrm{~km}$ \\
Average stress drop & $\mathrm{N} 40^{\circ} \mathrm{E}$ \\
Model size & $4.5 \mathrm{MPa}$ \\
Space step & $210 \mathrm{~km} \times 140 \mathrm{~km} \times 140 \mathrm{~km}$ \\
Time step & $1 \mathrm{~km}$ \\
Dynamic friction coefficient & $0.1 \mathrm{~s}$ \\
Static friction coefficient & 0.6 \\
Initial shear stress & 0.8 \\
Initial normal stress & $-35 \mathrm{MPa}$ \\
Viscous parameters & 0.08 \\
Stiffness parameters & 0.3 \\
\hline
\end{tabular}

\section{The Computation Result}

Applying explicit finite-element method, we compute the ground motion of Tangshan earthquake. Here, we give the velocity of ground motion at the $4 \mathrm{~km}$ to the seismic fault from the east side of central of Tangshan fault. The Figures 2 and 3 are the ground motion component in vertical and parallel to the fault strike direction. Figure 4 is the ground motion component in vertical ground surface direction. Figures $\mathbf{2 - 4}$ give the velocity varying with time in 40 seconds.

Figure $\mathbf{2}$ is the velocity of ground motion component vertical to the strike direction. From the Figure 2, we can find that the strike slip motion of fault can also bring the ground motion vertical to the fault strike direction. The maximum of ground motion vertical to strike direction is

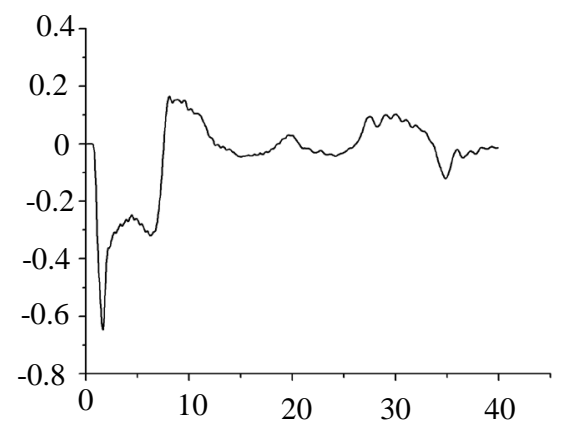

Figure 2. The ground velocity component vertical to fault strike direction.

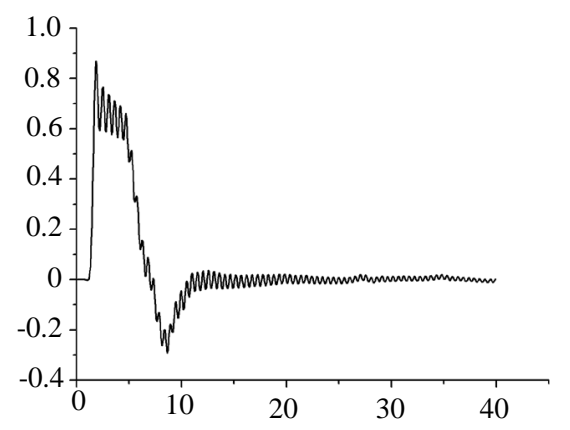

Figure 3. The ground velocity component parallel to fault strike direction.

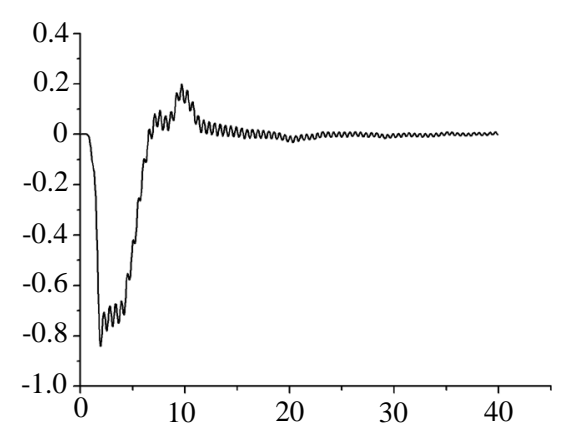

Figure 4. The ground velocity component vertical to ground surface. 
$0.65 \mathrm{~m} / \mathrm{s}$. Figure 3 is the velocity of ground motion component parallel to the strike direction. Because the Tangshan earthquake is a special strike event, the ground motion parallel to strike is the mainly character of ground motion. The maximum of ground motion parallel to strike direction is $0.9 \mathrm{~m} / \mathrm{s}$ and is larger than that of component vertical to strike direction and ground surface. Figure 4 is the velocity of ground motion component vertical to the ground surface. The maximum of ground motion vertical the ground surface is $0.85 \mathrm{~m} / \mathrm{s}$ and larger than that of component vertical to strike direction. Comparing the maximum of our computational result with other scholar's computation, we find our computational result is very near to theirs, which shows our achievement is reasonable.

Comparing the above three computational result figures, when the earthquake happens due to the strike slip movement of strike fault, the main motion of ground surface is parallel to the fault strike direction and vertical to the ground surface. And these two kind motions have the high frequency vibration at the same time, which can be seen from the Figures 3 and $\mathbf{4}$. Since the computational spot is $4 \mathrm{~km}$ to the Tangshan fault, the three ground motion component almost begin at the $1-2$ second. Because in earthquake, the $\mathrm{S}$ wave is mainly factor to cause damage, the corresponding time of maximum of ground motion vertical to ground surface and parallel to strike direction almost equals to the time of S-wave travel to the computational spot.

\section{Acknowledgements}

This work is supported by the China Earthquake Administration through "Earthquake Backbone Technology Professionals Foundations" and "Discern and evaluation of earthquake risk zone (2012BAK15B01)”. Thank Shuo Ma for his providing the computation code to calculate.

\section{REFERENCES}

[1] J. Lysmer and L. A. Drake, “A Finite Element Method for
Seismology,” In: B. Alder, S. Fernbach and B. A. Bolt, Eds., Methods in Computational Physics, Vol. 11, Academic Press, New York, 1972.

[2] V. Pereyra, E. Richardson and S. E. Zarantonello, "Large Scale Calculations of 3D Elastic Wave Propagation in a Complex Geology,” Proceedings Supercomputing, 1992, pp. 301-309.

[3] E. Kim, J. Bielak and O. Ghattas, "Large-scale NorthRidge Earthquake Simulation Using Octree-Based Multireslution Mesh Method," Proceedings of the 16th ASCE Engineering Mechanics Conference, Seattle, July 2003.

[4] S. M. Day, "Three-Dimensional Simulation of Spontaneous Rupture: The Effect of Nonuniform Prestress,” Bulletin of the Seismological Society of America, Vol. 72, 1982, pp. 1881-1902.

[5] D. D. Oglesby, R. J. Archuleta and S. B. Nielsen, "Earthquakes on Dipping Faults: The Effects of Broken Symmetry," Science, Vol. 280, No. 5366, 1998, pp. 10551059. http://dx.doi.org/10.1126/science.280.5366.1055

[6] T. J. R. Hughes, "Finite Element Method_-Linear Static and Dynamic Finite Element Analysis,” Prentice-Hall, Englewood Cliffs, 1987.

[7] G. L. Gourdreau and J. O. Hallquist, "Recent Developments in Large Scale Finite Elements Lagrangian Hydrocode Technology," Computer Methods in Applied Mechanics and Engineering, Vol. 33, No. 1-3, 1982, pp. 725757. http://dx.doi.org/10.1016/0045-7825(82)90129-3

[8] T. Belytschko, J. S. Ong, W. K. Liu and J. M. Kennedy, "Hourglass Control in Linear and Nonlinear Problems," Computer Methods in Applied Mechanics and Engineering, Vol. 43, No. 3, 1984, pp. 251-276. http://dx.doi.org/10.1016/0045-7825(84)90067-7

[9] D. Kosloff and G. A. Frazier, "Treatment of Hourglass Patterns in Low Order Finite Element Codes,” International Journal for Numerical and Analytical Methods in Geomechanics, Vol. 2, No. 1, 1978, pp. 57-72. http://dx.doi.org/10.1002/nag.1610020105

[10] S. Ma and L. Peng, "Modeling of the Perfectly Matched Layer Absorbing Boundaries and Intrinsic Attenuation in Explicit Finite-Element Methods," Bulletin of the Seismological Society of America, Vol. 96, No. 5, 2006, pp. 1779-1794. http://dx.doi.org/10.1785/0120050219 